This is the accepted manuscript of the article, which has been published in Widening Participation and Lifelong Learning. 2019, 21(2), 190-208. https://doi.org/10.5456/WPLL.21.2.190

\title{
Acknowledging the Head, Heart, Hands and Feet: Research with Refugees and People Seeking Asylum in Higher Education
}

\author{
Kristin Reimer, Monash University \\ Email: kristin.reimer@monash.edu \\ Mervi Kaukko, Monash University \\ Karen Dunwoodie, Deakin University \\ Jane Wilkinson, Monash University
}

Sue Webb, Monash University

\begin{abstract}
In this article, we focus on the ethical complexities of conducting research with people from refugee and asylum-seeking backgrounds. We provide a critical reading of existing literature using Sevenhuijsen's (1998) framework of the head, heart, hands and feet of research ethics. In this metaphor, the head refers to the rational approach to ethics, heart to the emotional and intuitive response to ethics, hands to the practical engagement with ethics and feet to the way forward. We argue that traditional and ethical guidelines prescribed by higher education institutions are not sufficient to prepare researchers for the unique complexities of working with refugees and people seeking asylum. Instead, alongside such prescribed and rational approaches, we must also engage the heart, hands and feet. Our aim is to consider how research conducted with students from refugee and asylum-seeking backgrounds can be approached in a holistic and ethical manner.
\end{abstract}

Key words refugee; asylum-seeking; higher education; ethics

\section{Introduction}

Ethical and methodological perspectives on research with refugees and people seeking asylum have been explored extensively in recent years (Bailey and Williams, 2018; Thapliyal and Baker, 2018; Gillam, 2013; Hugman et al., 2011). Although universities have remained largely outside the purview of refugees and people seeking asylum, 'there is a small but burgeoning body of literature examining the experiences of refugee background students in higher education. This research has identified, among other issues, the difficulties in re-establishing lives while facing multiple barriers (Fagan et al., 2018; Guo, 2010; Naidoo et al., 2018) as well as the tendency of policymakers, institutions and educators to misrecognise the strengths, challenges and experiences that students from refugee and asylum-seeking backgrounds bring to higher education (Fagan et al., 2018; Hartley et al., 2018; Naidoo et al., 2018). This initial research implies unique considerations for such students that are relevant to the design of research 
protocols, and that also warrant the need for further examination of the ethical and methodological dimension of researching the refugee and asylum-seeking population specifically in higher education institutions.

In response to the growing research interest, this article addresses the ethical complexities of research with students from refugee and asylum-seeking backgrounds in higher education. We provide a critical reading of existing literature using Sevenhuijsen's (1998) framework of the head, heart, hands and feet of research ethics. In this metaphor, the head refers to the rational approach to ethics, heart to the emotional and intuitive response to ethics, hands to the practical engagement with ethics and feet to 'the practice of walking the moral path in order to get things done' (Houston, 2012: 653). We approach our topic by using narrative literature review as a method. Rather than systematically reviewing all literature in the field, a narrative literature review allows us to create a narrative, or a story, of purposefully chosen studies around this theme. This story tells us that traditional and ethical guidelines (head) prescribed by higher education institutions are not sufficient in preparing researchers for the unique complexities of working with students from refugee and asylum-seeking backgrounds. Instead, alongside such rational approaches, we must also engage the heart, hands and feet. Our aim is to consider how research conducted with students from refugee and asylum-seeking backgrounds can be approached in a holistic and ethical manner. We reflect on our own approach to ethics as we research the experiences of students from refugee and asylum-seeking backgrounds in higher education in Australia.

\section{Australian context}

The world is still attempting to evaluate the overall effect of the current global refugee situation. The latest figures indicate there are 68.5 million internally as well as externally displaced persons worldwide (United Nations High Commissioner for Refugees [UNHCR], 2018) with 50 per cent of the 22.5 million registered refugees consisting of children under the age of 18 (UNHCR, 2018). Australia, despite its remote location, has by no means escaped this phenomenon. Currently, there are approximately 30,000 people without permanent protection in Australia, all of whom are attempting to settle and re-establish their livelihoods (Refugee Council of Australia [RCOA], 2017).

Individuals seeking asylum are people who move across borders in search of protection. An 'asylum seeker' is someone 'who has applied for protection as a refugee and is awaiting the determination of their status' (RCOA, 2016). The 1951 Refugee Convention (signed by 145 countries including Australia, [UNHCR, 2011]) defines a refugee as:

'Any person who owing to a well-founded fear of being persecuted for reasons of race, religion, nationality, membership of a particular social group or political 
opinion, is outside the country of his/her nationality and is unable, or owing to such fear, is unwilling to avail himself/herself of the protection of that country.' (UNHCR, n.d.: 3)

Asylum seekers can become refugees if the host country or refugee authority (e.g. UNHCR) deems them as fitting the international definition of refugee. Many refugees have at some point been asylum seekers, that is, they have lodged an individual claim for protection and have had that claim assessed by a government or by the UNHCR. Application for asylum and refugee resettlement is a significant step, following upheaval and flight from persecution. For many, it is assumed that the host country will provide not only safety, but also future opportunities for permanent residence, employment and education.

In the Australian higher education sector, applicants from refugee and asylumseeking backgrounds are categorised as international students and therefore required to pay full international tuition fees. For the vast majority, these fees are unaffordable. In recognition of this policy problem, 19 of the 43 Australian universities offered fee waivers and/or financial bursaries to students from refugee and asylum-seeking backgrounds in 2018 (RCOA, 2018). Thus, as students with refugee and asylum-seeking backgrounds gain more access to higher education institutions, it is imperative that we conduct research on their experiences. This enables us to identify issues and strengthen the potential that this group of students has equal opportunities to engage positively with university studies. It is, however, just as imperative that we ensure that any research conducted with and on students from refugee and asylum-seeking backgrounds is approached in a holistic and ethical manner.

\section{The head, heart, hands and feet of research ethics with refugees and people seeking asylum}

In Citizenship and the Ethics of Care, Selma Sevenhuijsen (1998) builds on Carol Gilligan's (1982) work on the nature of care from a feminist perspective by proposing a metaphor of head, heart, hands and feet of ethics. Similar metaphors are used for example in reference to professional ethics in education (Sharma, 2018; Shulman, 2004), transformative learning (Singleton, 2015) and intercultural learning (Barratt Hacking et al., 2016). We find the metaphor particularly suitable when considering research ethics in complicated fields, such as research with students from refugee and asylum-seeking backgrounds. In this article, we use the metaphor to discuss research ethics as official principles (procedural ethics, head), relationships, emotions and intuitions (relational ethics, heart), the practical implementation of ethical research (hands), and finally, the potential for transformation through research (feet).

\section{The head of research ethics}


The head of research ethics is where the thinking begins. Questions are formulated as to the aims of the research, who to include, how to include them and what specific considerations are to be brought to bear in each particular research project.

This is also the first moment - isolated from the commotion of the field and the urgency of immediate decisions - with which the notion of harm is engaged. We know that research involving people has great potential to put them at risk (Goodyear-Smith et al., 2015; Drake, 2014; Pittaway et al., 2010; Sikes, 2006). We also know that we, as researchers, are the ones putting people at risk by inviting their participation, largely for our own benefit, and through the research decisions that we make (Goodyear-Smith et al., 2015; Sikes, 2006; Guillemin and Gillam, 2004). It is beyond the scope of this article to discuss all the ways in which populations from refugee and asylum-seeking backgrounds are 'at risk' already due to their situation, and how research can unintentionally harm. ${ }^{\text {ii }}$ It is, however, vital that we engage our heads fully as we consider how, at the very least, to do no harm with this particular group of participants.

The head of research ethics is concerned with procedural ethics, which is, largely, aimed at gaining consent and attending to 'generalized and context independent risks of research' (Block et al., 2012: 70, emphasis in original). The need for policies and procedures to ensure research does not inflict harm on participants is largely thought to have been identified in response to the horrors committed by Nazis in the name of medical research (Hugman et al., 2011; Guillemin and Gillam, 2004). Resulting from these horrendous revelations were the 1949 Nuremburg Code and, later, the Declaration of Helsinki (World Medical Association, 1964). Within these codes were explicit requirements for medical researchers to receive consent from participants and to ensure that participants experienced no harm as a result of research. These two tenets of ethical research practice permeate ethical discourse today (Hugman et al., 2011; Guillemin and Gillam, 2004).

Formal codes of research practice then emerged - both nationally and institutionally - often initially focused on biomedical research but later extending to include all forms of social research (Drake, 2014; Hugman et al., 2011; Guillemin and Gillam, 2004). In Australia, ethics guidelines emanate from the National Health and Medical Research Council (NHMRC). Australian universities are required to comply with the National Statement on Ethical Conduct in Human Research (NHMRC, 2018) and thus have instituted committees and formal processes to ensure that research taken in the university's name adheres to ethical standards.

At Monash University, where we work and study, this process is the purview of the Monash University Human Research Ethics Committee (MUHREC). The MUHREC considers 'issues that constitute integrity, respect for persons, beneficence, justice, consent, research merit and safety' with the aim of 
protecting 'the welfare and the rights of participants in research' (Monash Research Office, 2018). Every proposed research project must be checked to ensure that the methodology of the project is well-considered and that potential harm has been minimised. Although such procedures receive criticism for their bureaucratic inflexibility, there is broad agreement that such 'a stringent and transparent system of governance is preferable to a repeat of past scandals' (Goodyear-Smith et al., 2015: 3).

Our focus is on the ethics of conducting research with refugees and people seeking asylum. Given the increased interest in this field, Kaukko et al. (2017) highlight the growing number of novice researchers working with refugees and people seeking asylum. Participants from refugee and asylum-seeking backgrounds are widely acknowledged to be in vulnerable and precarious positions (McLaughlin and Alfaro-Velcamp, 2015; Pittaway et al., 2010) in their new land and often bear 'the weight of the conflicts, abuse, torture and trauma which led to their forced migration in the first place' (Darling, 2014: 202). Such past and current positions require heightened attention to ethics. Procedural ethics can instigate this attention.

Researchers have raised numerous aspects unique to participants from refugee and asylum-seeking backgrounds that must be noted when designing and conducting research. Several of these are first considered in formal ethics procedures: gaining appropriate access (Hugo, 2011; Ellis et al., 2007); practicalities of informed consent (Hirsch and Maylea, 2016; Riggs et al., 2015; Hugman et al., 2011; Ellis et al., 2007); translation needs (Hirsch and Maylea, 2016); realistic timetables for gaining trust (Darling, 2014); inappropriate methodologies (Hugo, 2011) among others.

The strengths of such procedural ethics are that they provide what Guillemin and Gillam (2004) refer to as an 'ethics checklist', which reminds researchers to note crucial risks, ensure confidentiality, and tailor consent to their participants. In considering conducting research with refugees and people seeking asylum, the checklist, as a bare minimum, is crucial. The procedural ethics checklist is a chance for novice and experienced researchers to pause and consider how to ensure that participants do not experience research 'as exploitation' (McLaughlin and AlfaroVelcamp, 2015: 28). Yet, the consideration of these aspects in formal ethics procedures is only a starting point. To ensure that procedural ethics are assessed more accurately, Ellis et al. (2007) recommend that ethics review boards engage members of the refugee community to review such proposals. This would be a welcomed step. Yet, procedural ethics are limited in their scope as they seek to 'render the ethical outcomes of research encounters predictable' (Thrift, 2003: 119). Research encounters are never predictable. Thus, most researchers engaging with refugees and people seeking asylum insist that we do more than no 
harm, that we exceed procedural ethics and engage more than just the head of research ethics. Thus, we consider the heart of research ethics.

\section{The heart of research ethics}

The heart refers to how we interpret the procedural ethical guidelines, and what we value as ethical research. The heart focuses on emotion, relational connectedness, empathy, the pursuit of virtue and inductive 'know-how' when working with research participants. As Houston (2012: 659) argues, 'coming from the "heart", ethical responses reflect a spontaneity grounded in the "here" and "now" - an accurate tuning-in to the situation, rather than a more distanced, calculative and deliberative reaction.' For Sevenhuijsen (1998), the heart is the source of attentiveness, responsiveness and responsibility for the other.

Attentiveness and responsibility for the other can enable researchers to add a situational and personal element into rational choices made in the head. Some studies (Moore et al., 2018; Hugman et al., 2011) indicate research that formally follows all ethical guidelines can still fail to address significant issues if the researcher is not aware of, or not fully interested in, the participants' well-being. As noted already, what constitutes 'harm' and 'benefit' with refugees and people seeking asylum are complicated questions, and researchers can do harm while genuinely trying to work with the best intentions. The problem with procedural ethics is that as they are meant to be general, they can also be simplistic and overbureaucratic, and thus fail to acknowledge how risks and benefits play out in a myriad of ways in different situations (De Graeve and Bex, 2016; Gillam, 2013; Rossman and Rallis, 2010). For example, requests to record interviews, take photographs or sign forms can confuse or worry participants from refugee and asylum-seeking backgrounds. Recording, photos and signatures are all part of normal research and within the ethical guidelines. However, they are also part of procedures connected to the asylum application and border control, and can for that reason feel confusing and intimidating. Paying attention to the heart ethics can warn the researcher of their risks, remind them to ensure that sufficient background work is being done, and that the research participants will not confuse research with immigration procedures.

On the one hand, it has been argued that ethical decisions made in the heart are not tied to time or space; they are part of who we are and how we work.

However, just like normative ethics, this includes a risk of becoming too vague or simplistic and overlooking the needs of refugees and people seeking asylum. We argue that research with refugees and people seeking asylum requires certain specificity, and the interest and commitment to 'do no harm' should be tied to the life situations of the particular participants in the particular space and time. To be able to make personal and situational ethical judgements, researchers need to know his or her participants and their situations. Ethical research relationships, viewed from this perspective, come to life as multiple questions rather than 
certain answers; as a process rather than single moments or events; and as a reflective approach rather than as a set of norms (Kaukko et al., 2019; Hugman et al., 2011).

Our ongoing study seeks to understand the experiences of refugee and asylumseeking students from seven universities across Australia, as they engage in the process of accessing and participating in higher education. We are learning from the participants over the course of their engagement in university study, and thus forming relationships with them and earning their trust over multiple years. The key interviewer has, in divergent ways and in the context of different projects and volunteer roles, worked alongside people from refugee and asylum-seeking backgrounds since 2010 . Through her work, she has become immersed in the complexities and challenges faced by the refugee community. In collecting data for this research, we recognise that a precondition driving our commitment to personal and situational ethical judgements is the continued support and regular informal meetings we have with the participating students.

Equally important factors are genuine interest in the research participants' wellbeing and reciprocal trust. As the interviewer learns each person's unique story and unique concerns, she adjusts her interview questions and her responses accordingly. She has relayed that it is often once the recording device is turned off, that participants voice their most immediate queries and issues.

As our example shows, we see the heart of research ethics as inductive knowhow, relational connectedness and a situational perspective of what might be beneficial for the research participants. Although researchers can use their head independently to make rational choices about procedural ethics, relational ethics take place between people. Similarly, although the head ensures that choices are not based on our unquestioned interpretation of risk or benefits but made after careful and rigorous thought, the heart ensures that choices are also based on attentiveness and responsiveness to the specific situation of research participants. The heart directs our attention to the ways in which ethical choices weave through all aspects of research relationships, not only the critical phases that call for detailed attention in forms.

We believe that approaching ethical decisions with the heart is something inherent to all people; as humans, we intimately understand the importance of working relationally and with empathy. Yet, making ethical decisions with the heart also does not happen just by chance, by filling in the ethics checklist. Official guidelines must give the time and space for the possibility to use the heart in research.

Arising from a collaboration of the head and heart, the hands are how research practice is conducted with care, support and compassion within real-life, situational contexts. In other words, 'the hand is a form of practical action that 
transcends a limited, traditional justice orientation and an uncritical application of care' (Houston, 2012: 659). The next section considers the hands of research ethics.

\section{The hands of research ethics}

Guillemin and Gillam (2004: 263) differentiate between the process of seeking formal approval, which they term 'procedural ethics' from 'ethics in practice', the everyday contextualised ethics. So, what does 'ethics in practice' look like with refugees and people seeking asylum? To answer this question, we briefly sketch two studies that were carried out by one of the researchers with refugees and people seeking asylum to illustrate how the principles and values explicated in the ethical guidelines noted earlier can be enacted in practice. These are not the only ways in which such research can be conducted but they do provide concrete examples of the practical implementation of ethical research with refugees and people seeking asylum, i.e., the hands.

Both studies were with young people of refugee background aged 12-22 years. The first study examined the role that everyday learning spaces such as sport, church and youth groups played in cultivating a pro-educational habitus for refugees and people seeking asylum in two regional Australian towns (Wilkinson et al., 2017; Santoro and Wilkinson, 2016). The second study examined the development of information literacies through the participation of refugees and people seeking asylum in invisible but crucial everyday spaces of learning such as public libraries, social media, faith groups, sporting clubs and shopping malls (Lloyd and Wilkinson, 2017; 2016). Both studies were based on the hypothesis that these often overlooked crucial everyday spaces of learning and knowing that provided alternative educational trajectories to support the educational achievement of refugees and people seeking asylum in formal educational institutions such as universities and schools. Our key dilemma was how to capture these hidden spaces in ethically informed and enabling ways that did not speak for or dehumanise potential participants. We asked ourselves how could we work with refugees and people seeking asylum in ways which built 'relationships of dignity and care ... for both researchers and participants', recognising that this was both 'ethically necessary' and would increase the validity of the research (Paris, 2011: 137)? We also understood that our approach needed to be inclusive, seeking to build trust and be 'humanising rather than colonising' (Paris, 2011: 137).

To achieve these aims, we undertook several steps. Firstly, a member of the research team was a long-standing elder among communities of refugee background in the local regional area. His relationship with families and agencies who worked with refugees and youth seeking asylum allowed him to assume a key role as a cultural mediator between the local Sudanese communities and the research team. Secondly, we built an 'early familiarity' (Shenton, 2004: 65) with 
the communities through preliminary visits and discussions with individuals, families and community agencies and organisations who had a long-term relationship of trust with potential participants. Thirdly, to build ethical 'relationships of dignity and care' between participants and researchers and to increase the credibility of the research (Paris, 2011: 137), an advisory committee was established. It consisted of representatives from the African Elders committee, community agencies dealing with refugee youth and education providers such as the New South Wales Education Department's local equity officer. They advised not only on the study design but also provided feedback on emergent themes and findings (Cohen et al., 2011).

Finally, in both studies, we employed photovoice methodology, an approach in which, using their mobile phones, participants took photographs of people, places and networks that they felt were supporting their educational achievements (Wilkinson et al., 2017; Santoro and Wilkinson, 2016); or the types of information and information sources that were important to them and the places where that information is located (Lloyd and Wilkinson, 2017; 2016). Participants then selected three to five photographs that they felt best captured the people, places and networks (Wilkinson et al., 2017; Santoro and Wilkinson, 2016) or the types and sources of information (Lloyd and Wilkinson, 2017; 2016) that supported their integration and learning. They were asked to discuss the selection of these photos. The process involved a 'more inductive research approach' (Clark-lbanez, 2004, as cited in Gotschi et al., 2009: 293) and provided a valuable means by which participants selected and told their own stories (Gotschi et al., 2009: 293). It shaped an action-oriented purpose so that the method became 'a tool ... that enable[d] people to define for themselves and others ... what [was] worth remembering and what need[ed] to be changed' (Wang, 2005, as cited in Gotschi et al., 2009: 294). These practical choices are how the hands of research consider both the head and the heart.

We now turn to the final section of the paper to examine the notion of the feet.

\section{The feet of research ethics}

The metaphor of feet brings to mind that feet ground people in spaces and relationships, as well as give people the ability to move or relate differently to one another. Consequently, in considering the role of the feet of researchers in relation to research ethics, our narrative literature review has identified the importance of the context and the inter-relational practices of research. Arguably such recognition is crucial for research with students from a refugee and asylumseeking background for whom accessing university experiences are complex and contested, and may involve environments and institutions where opportunities are inhibited and identities and spaces for action constrained. Recognition of these contexts is a practical and a moral imperative, as Wildemeersch (2017: 113) highlights, citing Jarvis's comments on the effects of new encounters on people's 
learning: 'When my spontaneity is inhibited by the presence of the Other, that is the beginning of ethics' (Jarvis, 1997). In other words, the inclusion of feet in a framework for research ethics brings in an activist aspect that not only adds to the concerns of the hands to recognise different people's voices, but also identifies what needs to be done to move forward and promote human well-being. In these ways, the activist element of research ethics ensures that attention is given to the politics and institutional arrangements that affect the policies and resource opportunities (economic, cultural, educational and symbolic) encountered by the researchers and the research participants.

Yet, feet are not planted in neutral land. Researchers have to ask themselves whose side they are on (Becker, 1967). This question reflects the issue of the relationship between research and social change and transformation that can be traced back through the critical social realism research strand (Becker, 1967) and second wave feminist writing on research and praxis, which still has resonance (Nagy Hesse-Biber, 2012). Where Gilligan's (1982) seminal work on the ethics of care argued that a feminist view of care should lead to 'politicised practices aimed at pressing institutional questions where women's voices have equal claim to those of men' (Houston, 2012: 657), it could be posited that the diverse voices of other socially excluded groups, such as refugees and asylum-seeking people, should also have an equal claim for attention. Giving attention to these other voices becomes then an ethic of resistance to injustice; the feet of a framework for research ethics need to identify how they will walk the moral path to make a difference and improve people's lives.

Turning to how to walk this moral path, discussions within the field of adult education provide useful concepts with which to think; they attend to the moral challenges faced by educators and practitioners who seek to enhance democratic practices. Specifically, in the context where migration from poorer and unsafe regions to richer and relatively safe regions of the world has grown substantially, issues of identity have come to the fore over capitalism's interest, suggests Habermas (2016). Any optimism associated with multiculturalism is being challenged by conservative voices (Wildemeersch, 2017). A politics of rebordering is dominating who can enter a country and have access to education, lifelong learning and different types of employment (Webb, 2017). Wildemeersch (2017) argues that these challenges oblige practitioners and scholars of adult education - and we would add researchers - who wish to walk the moral path, to reflect on the extent to which education provides for integration by promoting citizenship as an activity (not merely a status or an identity) in which all voices are enabled to be heard. In developing these ideas, Biesta's three approaches to public pedagogy are drawn on by Wildemeersch (2017). Although it is not within the scope of this article to explore these issues further, it is useful to note that Biesta's pedagogy for the public focuses on the role of instruction and a deficit view of learners; pedagogy of the public conceives of educators as facilitators and 
encourages individuals to develop solutions to social problems; in contrast, $a$ pedagogy of publicness highlights a set of activities to enable people to become public actors and encourages educators to be disrupters of existing perceptions. Arguably substituting the term educator for the feet of the researcher, Wildemeersch's (2017) suggestions below provide the moral imperative for the feet of researchers working with refugees and asylum-seeking people who are seeking access to higher education.

'The educator is someone who interrupts the taken-for-granted assumptions of the audience or the public. In doing so, s/he introduces an element of dissensus, meaning that a heterogeneous element is brought into the common sense of the participants. Such an element of dissensus is a sign of plurality, and such a sign in its turn refers to the fact that in our human condition, life choices are not predetermined but are open to the freedom of subjects to choose among the plurality of possibilities that the world offers.' (Wildemeersch, 2017: 118-119)

\section{Conclusion}

The head, heart, hands and feet of research ethics when working with people from refugee and asylum-seeking backgrounds means embodying ethics fully: to engage intellectually, conceptually, rationally, emotionally, relationally, practically and morally with the what, how and why of research ethics.

At times, there will be tension: the head may be in tension with the heart when the procedural and relational ethics do not meet; the hands may be in tension with the feet when research progresses in unanticipated directions. Houston (2012: 667) encourages us to embrace these creative tensions as they open up the space for 'humility and a reverence for complexity and contradiction'. It is, perhaps, in this fully embodied creative tension that we can reflect, practise selfcriticism, and ask important questions of how we engage with research with refugees and people seeking asylum. It is, perhaps, here that we allow Becker's (1967: 239) question to be answered, moment by moment, decision by decision, practice by practice: 'whose side are we on?'. 


\section{References}

Bailey, L. and Williams, S. (2018) 'The Ethical Challenges of Researching Refugee Education', Qualitative Research Journal, 18, 4: 359-370.

Barratt Hacking, E., Blackmore, C., Bullock, K., Bunnell, T., Donnelly, M. and Martin, S. (2016) The International Mindedness Journey: School Practices for Developing and Assessing International Mindedness Across the IB Continuum. University of Bath Reports. [Online]. Available at https://www.ibo.org/globalassets/publications/ibresearch/continuum/international-mindedness-final-report-2017-en.pdf (accessed: 26 April 2019).

Becker, H. (1967) 'Whose Side Are We On?', Social Problems, 14, 3: 239-247.

Bilger, V. and Van Liempt, I. (2009) 'Introduction' in I. Van Liempt and V. Bilger (eds) The Ethics of Migration Research Methodology: Dealing with Vulnerable Immigrants, Brighton: Sussex Academic Press.

Block, K., Riggs, E. and Haslam, N. (2013) 'Ethics in Research with Refugees and Asylum Seekers: Processes, Power and Politics' in K. Block, E. Riggs and N. Haslam (eds) Values and Vulnerabilities: The Ethics of Research with Refugees and Asylum Seekers, Toowong, QLD: Australian Academic Press.

Block, K., Warr, D., Gibbs, L., and Riggs, E. (2012) 'Addressing Ethical and Methodological Challenges in Research with Refugee-background Young People: Reflections from the Field', Journal of Refugee Studies, 26, 1: 69-87.

Cohen, L., Manion, L., and Morrison, K. (2011) Research Methods in Education, Oxford: Routledge.

Darling, J. (2014) 'Emotions, Encounters and Expectations: The Uncertain Ethics of "the Field"', Journal of Human Rights Practice, 6, 2: 201-212.

De Graeve, K. and Bex, C. (2016) 'Imageries of Family and Nation: A Comparative Analysis of Transnational Adoption and Care for Unaccompanied Minors in Belgium', Childhood, 23, 4: 492-505.

Drake, G. (2014) 'The Ethical and Methodological Challenges of Social Work Research with Participants who Fear Retribution: To "Do No Harm"', Qualitative Social Work, 13, 2: 304-319.

Ellis, B.H., Kia-Keating, M., Yusuf, S.A., Lincoln, A. and Nur, A. (2007) 'Ethical Research in Refugee Communities and the Use of Community Participatory Methods', Transcultural Psychiatry, 44, 3: 459-481.

Fagan, S., Baker, S., Irwin, E., Dantas, J., Gower, S., Singh, S. and Taiwo, M. (2018) '(Re)Claiming social capital: Improving language and cultural pathways for 
students from refugee backgrounds into Australian higher education', 23 May, Department of Education and Training. [Online]. Available at http://apo.org.au/node/172891 (accessed: 26 April 2019).

Gillam, L. (2013) 'Ethical Considerations in Refugee Research: What Guidance Do Formal Research Ethics Documents Offer?' in K. Block, E. Riggs and N. Haslam (eds) Values and Vulnerabilities: The Ethics of Research with Refugees and Asylum Seekers, Toowong, QLD: Australian Academic Press.

Gilligan, C. (1982) In a Different Voice: Psychological Theory and Women's Development, Cambridge, MA: Harvard University Press.

Goodyear-Smith, F., Jackson, C. and Greenhalgh, T. (2015) 'Co-design and Implementation Research: Challenges and Solutions for Ethics Committees', BMC Medical Ethics, 16, 78: 1-5.

Gotschi, E., Delve, R. and Freyer, B. (2009) 'Participatory Photography as a Qualitative Approach to Obtain Insights into Farmer Groups', Field Methods, 21, 3: 290-308.

Guillemin, M. and Gillam, L. (2004) 'Ethics, Reflexivity, and "Ethically Important Moments" in Research', Qualitative Inquiry, 10, 2: 261-280.

Guo, S. (2010) 'Toward Recognitive Justice: Emerging Trends and Challenges in Transnational Migration and Lifelong Learning', International Journal of Lifelong Education, 29, 2: 149-167.

Habermas, J. (2016) Interview with Jürgen Habermas for Die Zeit, 7 July, pp. 3738.

Hartley, L., Fleay, C., Baker, S., Burke, R. and Field, R. (2018) People Seeking Asylum in Australia: Access and Support in Higher Education. National Centre for Student Equity in Higher Education, Curtin University, Perth, Western Australia. [Online]. Available at https://www.ncsehe.edu.au/wpcontent/uploads/2018/11/Hartley PeopleSeekingAsylum.pdf (accessed: 26 April 2019).

Hirsch, A. and Maylea, C. (2016) 'Education Denied: People Seeking Asylum and Refugees Trapped in Limbo', New Community, 14, 3: 19-24.

Houston, S. (2012) 'Engaging with the Crooked Timber of Humanity: Value Pluralism and Social Work', British Journal of Social Work, 42, 4: 652-668.

Hugman, R., Pittaway, E. and Bartolomei, L. (2011) 'When 'Do No Harm' Is Not Enough: The Ethics of Research with Refugees and Other Vulnerable Groups', British Journal of Social Work, 41: 1271-1287. 
Hugo, G. (2011) 'A Significant Contribution: The Economic, Social and Civic Contributions of First and Second Generation Humanitarian Entrants. Summary of Findings', Australian Government Department of Immigration and Citizenship. [Online]. Available at https://www.dss.gov.au/sites/default/files/documents/01 2014/economic-socialcivic-contributions-booklet2011.pdf (accessed: 26 April 2019).

Jarvis, P. (1997) Ethics and Education for Adults in a Late Modern Society, Leicester: NIACE.

Kaukko, M., Dunwoodie., K. and Riggs, E. (2017) 'Rethinking the Ethical and Methodological Dimensions of Research with Refugee Children', ZEP: Zeitschrift für Internationale Bildungsforschung und Entwicklungspädagogik, 40, 1: 16-21.

Kaukko, M., Korkiamäki, R. and Kuusisto, A.-K. (2019) 'Normatiivisesta etiikasta elettyyn kohtaamiseen: tutkimuksellista hengailua yksin tulleiden maahanmuuttajanuorten kanssa. [From Normative Ethics Towards Lived Encounters: Research-like Hanging Out with Unaccompanied Minors]' in Kaisa Vehkalahti and Niina Rutanen (eds.) Lasten ja nuorten tutkimuksen etiikka II [Ethics of Childhood and Youth Research II], Helsinki: Finnish Youth Research Network, in press.

Koser, K. (ed.) (2016) 'Unaccompanied Minors [Special issue]', Journal of Refugee Studies.

Lloyd, A. and Wilkinson, J. (2016) 'Knowing and Learning in Everyday Spaces (KALiEds): Mapping the Information Landscape of Refugee Youth Learning in Everyday Spaces', Journal of Information Science, 42, 3: 300-312.

Lloyd, A. and Wilkinson, J. (2017) 'Tapping into the Information Landscape: Refugee Youth Enactment of Information Literacy in Everyday Spaces', Journal of Librarianship and Information Science, 51, 1: 252-259.

McLaughlin, R.H. and Alfaro-Velcamp, T. (2015) 'The Vulnerability of Immigrants in Research: Enhancing Protocol Development and Ethics Review', Journal of Academic Ethics, 13, 1: 27-43.

Monash Research Office (2018) 'What is human research?'

https://www.intranet.monash/researchadmin/start/ethics/human/what-ishuman-research

Moore, T.P., McArthur, M. and Noble-Carr, D. (2018) 'More a Marathon than a Hurdle: Towards Children's Informed Consent in a Study on Safety', Qualitative Research, 18, 1: 88-107.

Nagy Hesse-Biber, S. (ed.) (2012) Handbook of Feminist Research: Theory and Praxis, London: Sage. 
Naidoo, L., Wilkinson, J., Adoniou, M. and Langat, K. (2018) Navigating Complex Spaces: Refugee Background Students Transitioning into Higher Education, Singapore: Springer.

National Health and Medical Research Council (2018) National Statement on Ethical Conduct in Human Research: 2007 (Updated 2018), [Online]. Available at https://www.nhmrc.gov.au/guidelines-publications/e72 (accessed: 26 April 2019).

Paris, D. (2011) “'A Friend Who Understands Fully": Notes on Humanizing Research in a Multiethnic Community', International Journal of Qualitative Research, 24, 2: 137-149.

Pittaway, E., Bartolomei, L. and Hugman, R. (2010) “'Stop Stealing Our Stories": The Ethics of Research with Vulnerable Groups', Journal of Human Rights Practice, 2, 2: 229-251.

Refugee Council of Australia (2016) 'Who is a refugee? Who is an asylum seeker?' [Online]. Available at https://www.refugeecouncil.org.au/who-is-a-refugee/2/ (accessed: 26 April 2019).

Refugee Council of Australia (2017) State of the Nation 2017: Refugees and people seeking asylum in Australia. [Online]. Available at https://www.refugeecouncil.org.au/publications/reports/state-nation-2017/ (accessed: 26 April 2019).

Refugee Council of Australia (2018) Scholarships for people seeking asylum and refugees on temporary visas. [Online]. Available at https://www.refugeecouncil.org.au/ourwork/scholarships-people-seekingasylum-refugees/ (accessed: 26 April 2019).

Riggs, E. Yelland, J., Szwarc, J., Casey, S., Chesters, D., Duell-Piening, P., Wahidi, S., Fouladi, F. and Brown, S. (2015) 'Promoting the Inclusion of Afghan Women and Men in Research: Reflections from Research and Community Partners Involved in Implementing a "Proof of Concept" Project', International Journal for Equity in Health, 14, 1: 1-10.

Rossman, G.B. and Rallis, S.F. (2010) 'Everyday Ethics: Reflections on Practice', International Journal of Qualitative Studies in Education, 23, 4: 379-391.

Santoro, N. and Wilkinson, J. (2016) 'Sudanese Young People Building Capital in Rural Australia: The Role of Mothers and Community', Ethnography and Education, 11, 1: 107-120.

Sevenhuijsen, S. (1998) Citizenship and the Ethics of Care: Feminist Considerations on Justice, Morality, and Politics, London: Routledge.

Sharma, U. (2018) 'Preparing to Teach in Inclusive Classrooms' in G.W. Noblit (ed.) Oxford Research Encyclopedia of Education, Oxford: Oxford University Press. 
Shenton, A.K. (2004) 'Strategies for Ensuring Trustworthiness in Qualitative Research Projects', Education for Information, 22, 2: 63-75.

Shulman, L.S. (2004) The Wisdom of Practice: Essays on Teaching, Learning and Learning to Teach, San Francisco: Jossey-Bass.

Sikes, P. (2006) 'On Dodgy Ground? Problematics and Ethics in Educational Research', International Journal of Research \& Method in Education, 29, 1: 105117.

Singleton, J. (2015) 'Head, Heart and Hands Model for Transformative Learning: Place as Context for Changing Sustainability Values', Journal of Sustainability Education, 9: 1-16.

Thapliyal, N. and Baker, S. (2018) 'Research with Former Refugees: Moving Towards an Ethics of Practice', Australian Universities' Review, 60, 2: 47-54.

Thrift, N. (2003) 'Practising Ethics' in M. Pryke, G. Rose and S. Whatmore (eds) Using Social Theory: Thinking Through Research, London: Sage.

United Nations High Commissioner for Refugees (n.d.) What is a Refugee? [Online]. Available at https://www.unhcr.org/what-is-a-refugee.html (accessed: 26 April 2019).

United Nations High Commissioner for Refugees (2011) States Parties to the 1951 Convention relating to the Status of Refugees and the 1967 Protocol. [Online]. Available at http://www.unhcr.org/3b73b0d63.pdf (accessed: 26 April 2019).

United Nations High Commissioner for Refugees (2016) Aiming Higher - The Other One Per Cent: UNHCR Education Report 2016. [Online]. Available at http://www.unhcr.org/en-au/aiming-higher.html (accessed: 26 April 2019).

United Nations High Commissioner for Refugees (2018) Figures at a Glance: Statistical Yearbooks. [Online]. Available at http://www.unhcr.org/en-au/figuresat-a-glance.html (accessed: 26 April 2019).

Webb, S. (2017) 'Narratives of Migration for Reframing Adult Education for Equity in Mobile Times', International Comparative Adult Education Research, International Yearbook of Adult Education, 40: 71-91.

Wildemeersch, D. (2017) 'Opening Spaces of Conversation: Citizen Education for Newcomers as a Democratic Practice', International Journal of Lifelong Education, 36: 112-128.

Wilkinson, J., Santoro, N. and Major, J. (2017) 'Sudanese Refugee Youth and Educational Success: The Role of Church and Youth Group in Supporting Cultural and Academic Adjustment and Schooling Achievement', International Journal of Intercultural Relations, 60: 210-219. 
World Medical Association (1964) WMA Declaration of Helsinki: Ethical Principles for Medical Research involving Human Subjects. [Online]. Available at https://www.wma.net/policies-post/wma-declaration-of-helsinki-ethicalprinciples-for-medical-research-involving-human-subjects/ (accessed: 26 April 2019).

${ }^{\mathrm{i}}$ Globally, only one per cent of refugees attend university (UNHCR, 2016).

ii See, for example, Bilger and Van Liempt (2009) for an overview of methodological dilemmas in research with vulnerable migrant groups, including refugee-background populations; Block et al. (2013) for the particular challenges of research with children and young people with a refugee background; and methodological and ethical issues in research with unaccompanied minors in Koser's (2016) special virtual issue. 